\title{
Clinical Pharmacokinetics of Clopidogrel and Its Metabolites in Patients with Cardiovascular Diseases
}

\author{
Marta Karaźniewicz-Łada • Dorota Danielak • \\ Paweł Burchardt $\cdot$ Lukasz Kruszyna • \\ Anna Komosa $\cdot$ Maciej Lesiak $\cdot$ Franciszek Główka
}

Published online: 15 October 2013

(C) The Author(s) 2013. This article is published with open access at Springerlink.com

\begin{abstract}
Background and Objective Approximately 5-40\% of patients treated with clopidogrel do not display an adequate antiplatelet response. Clopidogrel resistance may be caused by insufficient drug absorption or impaired metabolic activation of the drug. The aim of this study was to evaluate the pharmacokinetics of clopidogrel and its metabolites in plasma samples from patients treated with high and low doses of clopidogrel, to obtain a possible explanation for antiplatelet resistance.

Methods The study included patients receiving either a single $300 \mathrm{mg}$ loading dose of clopidogrel $(n=17)$ or a $75 \mathrm{mg}$ dose $(n=45)$ for at least 7 days before sample collection. The concentrations of clopidogrel and its metabolites-the inactive $\mathrm{H} 3$ and the pharmacologically active $\mathrm{H} 4$ isomers of the thiol metabolite and the inactive carboxylic acid metabolite-in plasma samples (stabilized with 2-bromo-3'-methoxyacetophenone) from three patients after $300 \mathrm{mg}$ and from 41 patients after $75 \mathrm{mg}$ of
\end{abstract}

M. Karaźniewicz-Łada $(\bowtie) \cdot$ D. Danielak · F. Główka Department of Physical Pharmacy and Pharmacokinetics, Poznan University of Medical Sciences, 6 Święcickiego Street, 60-781 Poznan, Poland

e-mail: mkaraz@ump.edu.pl

P. Burchardt

Division of Cardiology-Intensive Therapy, Department of Internal Medicine, Poznan University of Medical Sciences, 49 Przybyszewskiego Street, 60-355 Poznan, Poland

Ł. Kruszyna

Department of General and Vascular Surgery, Poznan University of Medical Sciences, 1/2 Długa Street, 61-848 Poznan, Poland

A. Komosa $\cdot$ M. Lesiak

First Department of Cardiology, Poznan University of Medical Sciences, 1/2 Długa Street, 61-848 Poznan, Poland the drug were determined using a validated high-performance liquid chromatography method with tandem mass spectrometry. The non-stabilized samples from the remaining patients were analysed using a validated capillary electrophoresis method. The calculated concentrations were used to determine the pharmacokinetic parameters of the analytes. The pharmacodynamic response to clopidogrel treatment, expressed as adenosine diphosphate-induced platelet aggregation, was measured using a Multiplate analyser.

Results The pharmacokinetic parameter values for the $\mathrm{H} 3$ and $\mathrm{H} 4$ isomers determined in the studied group of patients treated with clopidogrel $75 \mathrm{mg}$ (maximum plasma concentration $\left[C_{\max }\right] 5.29 \pm 5.54$ and $7.13 \pm 6.32 \mathrm{ng} / \mathrm{mL}$ for $\mathrm{H} 3$ and $\mathrm{H} 4$, respectively; area under the plasma concentration-time curve from time zero to time $t\left[\mathrm{AUC}_{t}\right]$ $7.37 \pm 6.71$ and $11.30 \pm 9.58 \mathrm{ng} \cdot \mathrm{h} / \mathrm{mL}$ for $\mathrm{H} 3$ and $\mathrm{H} 4$, respectively) were lower than those reported in healthy volunteers, according to the literature data. Platelet aggregation measured with a Multiplate analyser ranged between 37 and $747 \mathrm{AU} \cdot \mathrm{min}$. A significant correlation was found between the $C_{\max }$ of the active $\mathrm{H} 4$ isomer and platelet aggregation $(p=0.025)$.

Conclusion The $C_{\max }$ of the active $\mathrm{H} 4$ isomer and platelet aggregation measured by the Multiplate analyser may serve as markers of the patient response to clopidogrel therapy.

\section{Introduction}

The antiplatelet drug clopidogrel- $\mathrm{a}$ second-generation thienopyridine with an absolute $\mathrm{S}$ configuration at carbon 7-is widely used in the prevention of ischemic events. In the CAPRIE (Clopidogrel Versus Aspirin in Patients at Risk of Ischaemic Events) trial, clopidogrel was 
shown to be more effective than aspirin in reducing the risks of myocardial infarction, ischemic stroke and vascular death [1]. Despite the obvious advantages of clopidogrel, many clinical studies have shown that approximately $5-40 \%$ of patients treated with conventional doses of clopidogrel display inadequate antiplatelet responses, which may lead to serious cardiovascular complications [2]. The mechanisms underlying this phenomenon have not yet been confirmed. It has been suggested that reduced efficacy of clopidogrel may be caused by genetic polymorphisms of the transporters and enzymes participating in clopidogrel absorption and metabolic transformation, and by non-genetic factors [3]. The bioavailability of clopidogrel may be diminished because of secretion of the active drug by an efflux pump P-glycoprotein encoded by the multidrug resistance gene. This result may be reflected by visible inter-patient variability in the plasma concentrations of clopidogrel and its metabolites [4].

Clopidogrel is a pro-drug and requires complex metabolic activation in the liver. Up to $85 \%$ of the absorbed drug can be transformed by carboxyl esterases into a carboxylic acid derivative of clopidogrel (CLPM), the major metabolite circulating in the blood [5]. Although this metabolite is inactive, its determination in plasma was used to study the pharmacokinetics of clopidogrel in an indirect manner for many years, because plasma concentrations of the parent drug are very low [6]. Only $15 \%$ of the absorbed clopidogrel dose is transformed by isoenzymes of cytochrome P450 (CYP) 1A2, CYP2B6, CYP2C9, CYP2C19 and CYP3A4 to a thiol metabolite (CTM), which is responsible for the antithrombotic effect of clopidogrel [7]. CTM selectively and irreversibly inhibits adenosine diphosphate (ADP)-induced platelet aggregation by directly blocking ADP binding to the P2Y12 receptor located on the platelet surface [8]. Among the various CYP enzymes that catalyse the oxidative activation of clopidogrel, the CYP2C19 polymorphic variants $* 2$ and $* 3$ are mostly responsible for reduced exposure to CTM, leading to the decreased antiplatelet effect of clopidogrel in some patients [9]. CTM is a chiral compound and may exist as four isomers $(\mathrm{H} 1-\mathrm{H} 4)$, of which only $\mathrm{H} 3$ and $\mathrm{H} 4$ were present in the obtained clinical samples [10]. In vitro studies have confirmed that the $\mathrm{H} 4$ isomer can be considered as the only active circulating isomer of CTM $[9,11]$. Because of the analytical problems associated with low concentrations of the parent drug and the instability of its thiol derivative, only a small number of papers have focused on the pharmacokinetic aspects of clopidogrel treatment. The majority of these studies were performed in healthy volunteers and refer to the pharmacokinetics of the parent drug only [12] or one of the metabolites, either CTM $[9,13-16]$ or the inactive CLPM [17]. In the cited papers on CTM pharmacokinetics, the specific parameters characterizing the metabolite were calculated for the mixture of CTM isomers. Because only the $\mathrm{H} 4$ isomer is clinically relevant, such an approach may lead to overestimation of patient exposure to the active metabolite of clopidogrel. Only Tuffal et al. [10] distinguished between the pharmacokinetic parameters of the CTM isomers on the basis of their concentration in the plasma of healthy volunteers. That study was applicable only to CTM and did not consider the concentrations of clopidogrel or its main metabolite, CLPM. There is only one paper focusing on the pharmacokinetics of the parent drug and its two metabolites, CLPM and unstabilized CTM, in healthy volunteers. Because of the lack of a CTM standard, the concentration was approximated on the basis of the calibration curve prepared for clopidogrel [18].

Because the patient response to clopidogrel treatment may be affected by the presence of specific co-morbidities (e.g. diabetes mellitus, chronic renal disease or obesity) and by co-administered medications (e.g. proton pump inhibitors [PPIs]) [3], pharmacokinetic studies of clopidogrel and its metabolites would be especially useful in patients undergoing antiplatelet therapy. There are only a few reports on clopidogrel pharmacokinetics in patients treated with the drug. Erlinge et al. [19] reported the pharmacokinetics of CTM as a mixture of isomers in patients with diabetes. The pharmacokinetics of clopidogrel, CLPM and CTM were investigated in patients with myocardial infarction, but the concentrations of CTM were very low because it was likely not stabilized in plasma samples [20]. Moreover, Deray et al. [21] described the pharmacokinetics of clopidogrel and CLPM but not those of the CTM isomers in patients with renal function impairment.

The objectives of this study were to investigate the pharmacokinetics of clopidogrel and its metabolites-the pharmacologically active $\mathrm{H} 4$, and the inactive $\mathrm{H} 3$ and CLPM - in patients treated with high and low doses of clopidogrel, to measure the pharmacodynamic effect of clopidogrel and to estimate the pharmacodynamic-pharmacokinetic correlation.

\section{Patients and Methods}

\subsection{Study Population}

The study involved patients of Caucasian origin from central Poland undergoing elective coronary angiography, percutaneous coronary intervention, carotid artery stenting or peripheral artery interventions. Patients received an oral clopidogrel formulation under fasting conditions, either as a single $300 \mathrm{mg}$ loading dose $(n=17)$ or as a $75 \mathrm{mg}$ maintenance dose $(n=45)$ for 7 days prior to the 
procedure. Patients with acute myocardial infarction, malignancies, oral anticoagulation therapy with a coumarin derivative, treatment with a glycoprotein IIb/IIIa antagonist or other antiplatelet drugs except for aspirin, platelet count $<100,000 / \mu \mathrm{L}$, current liver dysfunction or impaired renal function (serum creatinine concentration $>2 \mathrm{mg} / \mathrm{dL}$ ) were excluded from the study. The study protocol was approved by the Ethical Committee at Poznan University of Medical Sciences, and all patients gave written informed consent for participation.

\subsection{Sample Collection}

Blood samples for quantification of plasma analyte concentrations were collected before administration of clopidogrel and at $0.5,1,2,3,4,6,12$ and $24 \mathrm{~h}$ after administration. A $7.5 \mathrm{~mL}$ aliquot of blood was drawn into collection systems containing ethylenediaminetetraacetic potassium salt (EDTA-K) [Sarstedt AG \& Co., Nümbrecht, Germany]. To stabilize the highly labile CTM, $37.5 \mu \mathrm{L}$ of a $500 \mathrm{mM}$ acetonitrile solution of 2-bromo-3'-methoxyacetophenone (MPB) was added to the systems, in accordance with the procedure reported by Takahashi et al. [16]. The plasma was separated by centrifugation for $10 \mathrm{~min}$ at $1,620 \times g$ and stored at $-25^{\circ} \mathrm{C}$ until further analysis.

\subsection{Chemicals}

(+)-S clopidogrel bisulfate (purity $99 \%$ ) and its carboxylic acid metabolite (CLPM; purity $99.6 \%$ ) were obtained from the Pharmaceutical Research Institute (Warsaw, Poland). The $3^{\prime}$-methoxyacetophenone derivatives of the clopidogrel thiol metabolite H3 (MP-H3) and H4 (MP-H4) isomers were a generous gift from Sanofi Aventis (Montpellier, France). Piroxicam, used as an internal standard, was obtained from Jelfa (Jelenia Góra, Poland). The alkylating agent MPB and formic acid (purity $>95 \%$ ) were purchased from Sigma-Aldrich Chemie (Steinheim, Germany). Acetonitrile (Merck, Darmstadt, Germany) was of the high-performance liquid chromatography (HPLC) gradient grade. De-ionized water was used to prepare a mobile phase for HPLC (Simplicity UV, Millipore, USA). Drugfree human plasma was obtained from the Regional Centre of Blood Donation (Poznań, Poland).

\subsection{Determination of Clopidogrel and its Metabolite Concentrations in Plasma}

In the samples stabilized with MPB (from 3 patients treated with clopidogrel $300 \mathrm{mg}$ and from 41 patients treated with $75 \mathrm{mg}$ ), the concentrations of clopidogrel, CLPM and the $\mathrm{H} 3$ and $\mathrm{H} 4$ isomers of CTM were measured by a validated HPLC method with tandem mass spectrometry (MS/MS)
[22]. Briefly, $250 \mu \mathrm{L}$ of plasma was spiked with $25 \mu \mathrm{L}$ of internal standard solution at a concentration of $100 \mathrm{ng} / \mathrm{mL}$. Protein precipitation was performed by adding $450 \mu \mathrm{L}$ of acetonitrile to each sample. The mixture was vortexed and centrifuged for $10 \mathrm{~min}$ at $22,570 \times g$ and a temperature of $20{ }^{\circ} \mathrm{C}$ before the supernatant was filtered using Mini Uni Prep filters (Whatman International Ltd., Maidstone, Kent, UK). The resulting filtrate was evaporated under a vacuum at $40{ }^{\circ} \mathrm{C}$, and the dry residue was reconstituted in $200 \mu \mathrm{L}$ of the mobile phase. A $25 \mu \mathrm{L}$ aliquot was injected onto the HPLC-MS/MS system. The HPLC analysis was performed on a chromatograph Agilent 1200, which was coupled to a 6410 B Triple Quadrupole tandem mass spectrometer (both from Agilent Technologies, Palo Alto, CA, USA). The analytes were separated in the Zorbax Plus C18 column [100 $\mathrm{mm} \times 2.1 \mathrm{~mm}, \quad 3.5 \mu \mathrm{m}]$ (Agilent Technologies, USA) at a column temperature of $40^{\circ} \mathrm{C}$. The mobile phase was a mixture of de-ionized water (A) and acetonitrile (B), both containing $0.1 \%(\mathrm{v} / \mathrm{v})$ formic acid. The gradient was as follows: 0-7 min linear from 42 to $90 \% \mathrm{~B}, 7-7.5 \mathrm{~min}$ return from 90 to $42 \% \mathrm{~B}$ and post-time of 5 min with $42 \% \mathrm{~B}$ for column equilibration. The mobile phase flow was set at $0.35 \mathrm{~mL} / \mathrm{min}$. The eluent from the HPLC column was introduced directly to the MS interface, using electrospray ionization in the positive ion mode. The MS parameters were as follows: capillary voltage $4,000 \mathrm{~V}$, nebulizer gas (nitrogen) pressure $40 \mathrm{psi}(275.8 \mathrm{kPa})$, desolvation gas (nitrogen) flow $10 \mathrm{~L} / \mathrm{min}$ and desolvation temperature $300{ }^{\circ} \mathrm{C}$. Nitrogen was used as a collision gas. The specific transitions for the analytes were monitored using the multiple reaction monitoring (MRM) mode. The most sensitive mass transition was from $\mathrm{m} / \mathrm{z} 322.1$ to 212 for clopidogrel, from $\mathrm{m} / \mathrm{z} 504.1$ to 155 for the CTM isomers, from m/z 308.1 to 198 for CLPM and from m/z 332.1 to 95 for the internal standard. The method was linear in the ranges of $0.25-5.00 \mathrm{ng} / \mathrm{mL}$ for clopidogrel, $0.25-50.00 \mathrm{ng} / \mathrm{mL}$ for the MP-H3 and MP-H4 isomers, and $50-10,000 \mathrm{ng} / \mathrm{mL}$ for CLPM. The lower limits of quantitation (LLOQs) were $0.25 \mathrm{ng} / \mathrm{mL}$ for clopidogrel, MP-H3 and MP-H4, and $50.00 \mathrm{ng} / \mathrm{mL}$ for CLPM. The intra- and inter-assay precision values, expressed as relative standard deviations, were $\leq 18.1 \%$ for clopidogrel, $\leq 15.2 \%$ for CLPM,$\leq 10.1 \%$ for MP-H3 and $\leq 19.9 \%$ for MP-H4. The intra- and inter-day accuracy of the method, expressed as the relative error, was $\leq 16 \%$. The analytes were stable in samples stored for $6 \mathrm{~h}$ in the autosampler, and in plasma samples stored for $24 \mathrm{~h}$ at room temperature and for 3 months at $-25{ }^{\circ} \mathrm{C}[22]$.

In plasma samples not treated with MPB (from 14 patients treated with clopidogrel $300 \mathrm{mg}$ and from 4 patients treated with $75 \mathrm{mg}$ ), only the concentrations of CLPM were measured by a validated high-performance capillary electrophoresis method with diode array 
detection, as described by Karaźniewicz-Łada et al. [23]. Briefly, $1 \mathrm{~mL}$ of plasma was mixed with $50 \mu \mathrm{L}$ of the internal standard at a concentration of $10 \mathrm{mg} / \mathrm{L}$ and $1 \mathrm{~mL}$ of phosphoric buffer at $\mathrm{pH}$ 5.0. The analytes were extracted by a solid-phase extraction procedure on $\mathrm{C} 18$ columns (Bakerbond $\mathrm{SPE}^{\mathrm{TM}}$; J.T. Baker, Deventer, The Netherlands) and determined on an Agilent model ${ }^{3 \mathrm{D}} \mathrm{CE}$ apparatus (Agilent Technologies, Waldbronn, Germany) with the ultraviolet detector set at $\lambda=220 \mathrm{~nm}$. The samples were automatically injected using a hydrodynamic injection at the anode. The temperature of the capillary was maintained by a thermostatic system at $25^{\circ} \mathrm{C}$. The separation was performed in a fused silica capillary, $35 \mathrm{~cm} \times 50 \mu \mathrm{m}$ i.d., $26.5 \mathrm{~cm}$ to the detector, filled with a $0.025 \mathrm{M}$ phosphate buffer of $\mathrm{pH} 2.5$. The system was controlled by ChemStation software. All experiments were performed at $25 \mathrm{kV}$ and a $50 \times 5$ mbar.s injection ( $12 \mathrm{~nL}$ injected volume). The method was linear in the range of $0.5-10 \mathrm{mg} / \mathrm{L}$ for clopidogrel and $0.25-20 \mathrm{mg} / \mathrm{L}$ for CLPM. The intra- and inter-day accuracy and precision of the method were below $12 \%$. The recovery of the analytes from plasma samples was $\geq 80 \%[23]$.

\subsection{Pharmacodynamic Assay}

Whole-blood platelet aggregation was measured in 38 patients receiving clopidogrel $75 \mathrm{mg}$ daily. The samples for the aggregation assay were collected, $2-3 \mathrm{~h}$ after clopidogrel administration, in an S-Monovette system coated with hirudin (Sarstedt AG \& Co.). The measurements were performed using an impedance aggregometer (Multiplate ${ }^{\circledR}$ analyser; Roche Diagnostics, Mannheim, Germany). After a 1:1 dilution of whole blood with $0.9 \%$ $\mathrm{NaCl}$ solution and stirring for $3 \mathrm{~min}$ in the test cuvettes at $37{ }^{\circ} \mathrm{C}, 6.4 \mu \mathrm{mol} / \mathrm{L}$ of ADP was added, and the increase in electrical impedance was recorded continuously for $6 \mathrm{~min}$. The platelet aggregation was quantified as arbitrary units (AU) and the area under the curve of the arbitrary units (AU.min). According to the recent consensus opinion of Bonello et al. [24], a cut-off point of $468 \mathrm{AU} \cdot \mathrm{min}$ for platelet aggregation in response to ADP should be used as the threshold for an increased risk of thrombotic events during clopidogrel therapy. All materials used for platelet function testing were obtained from the manufacturer.

\subsection{Pharmacokinetic Calculations}

The plasma concentrations of clopidogrel, CLPM, H3 and $\mathrm{H} 4$ were used to calculate the pharmacokinetic parameters, using WinNonlin version 6.2 software (Pharsight, Mountain View, CA, USA). For the calculation, the non- compartmental technique was applied. The total area under the concentration-time curve (AUC) was estimated by the trapezoidal rule with extrapolation from time zero to infinity $\left(\mathrm{AUC}_{\infty}\right)$, using $C_{\text {last }} / k_{\mathrm{el}}$, where $C_{\text {last }}$ is the last measurable concentration and $k_{\mathrm{el}}$ is the elimination rate constant calculated from the terminal linear segment of the log plasma concentration-time data. The elimination halflife $\left(t_{1 / 2}\right)$ was estimated from $\ln 2 / k_{\mathrm{el}}$. The maximum plasma concentration $\left(C_{\max }\right)$ and the time to reach the $C_{\max }\left(t_{\max }\right)$ were derived directly from the observed plasma concentrations. The plasma drug clearance $(\mathrm{CL} / F)$ was calculated by dividing the dose $(D)$ of each enantiomer by the $\mathrm{AUC}_{\infty}$, assuming complete biological accessibility. The volume of distribution $\left(V_{\mathrm{d}} / F\right)$ was estimated from $D / k_{\mathrm{el}} \times \mathrm{AUC}_{\infty}$.

\subsection{Statistical Analysis}

The statistical analysis was performed using Statistica version 8.0 software (StatSoft Inc., Tulsa, OK, USA). The coefficient of variation (CV \%) was calculated as (mean/ $\mathrm{SD} \times 100)$. Normality was estimated with the ShapiroWilk test. The differences between the normally distributed variables were determined with the Student's $t$ test; in the other cases, the Mann-Whitney test was applied. Correlations between the parameters were calculated with the Spearman rank correlation coefficient for all non-normally distributed values. A $p$ value of $<0.05$ was considered significant.

\section{Results}

\subsection{Patient Characteristics}

The detailed characteristics of the subjects are presented in Table 1 . No statistically relevant differences were observed in the age, bodyweight and body mass index between the patient groups.

\subsection{Determination of Clopidogrel and Its Metabolite Concentrations in Plasma}

The mean plasma concentration-time profiles of clopidogrel, CLPM and the H3 and H4 isomers of CTM obtained in patients following administration of clopidogrel at doses of 75 and $300 \mathrm{mg}$ are presented in Fig. 1. As suggested by Tuffal et al. [10], the samples with poor signs of haemolysis after addition of MPB (48 out of a total of 358 samples) were considered as not sufficiently stabilized, and their concentrations of $\mathrm{H} 3$ and $\mathrm{H} 4$ were not taken into account during the pharmacokinetic calculations. 
Table 1 Patient characteristics

\begin{tabular}{lll}
\hline Characteristic & Clopidogrel $75 \mathrm{mg}(n=45)$ & Clopidogrel $300 \mathrm{mg}(n=17)$ \\
\hline Age [years; mean $\pm \mathrm{SD}]$ & $63.0 \pm 8.5$ & $64.9 \pm 9.9$ \\
Bodyweight $[\mathrm{kg} ;$ mean $\pm \mathrm{SD}]$ & $81.8 \pm 13.3$ & $80.4 \pm 6.6$ \\
Body mass index $\left[\mathrm{kg} / \mathrm{m}^{2} ;\right.$ mean $\left.\pm \mathrm{SD}\right]$ & $27.8 \pm 5.4$ & $27.8 \pm 3.2$ \\
Female sex $[n]$ & 14 & 0 \\
Carotid artery stenting $[n]$ & 3 & 10 \\
Coronary angiography $[n]$ & 16 & 0 \\
Percutaneous coronary intervention $[n]$ & 25 & 0 \\
Peripheral artery intervention $[n]$ & 1 & 7 \\
Hypertension $[n]$ & 37 & 8 \\
Hypercholesterolaemia $[n]$ & 7 & 2 \\
Diabetes mellitus $[n]$ & 15 & 6 \\
Dyslipidaemia $[n]$ & 8 & 8 \\
Proton-pump inhibitors $[n]$ & 18 & 4 \\
Statins $[n]$ & 42 & 14 \\
Beta-blockers $[n]$ & 37 & 7 \\
ACE inhibitors $[n]$ & 30 & 9 \\
\hline
\end{tabular}

angiotensin-converting enzyme, $S D$ standard deviation
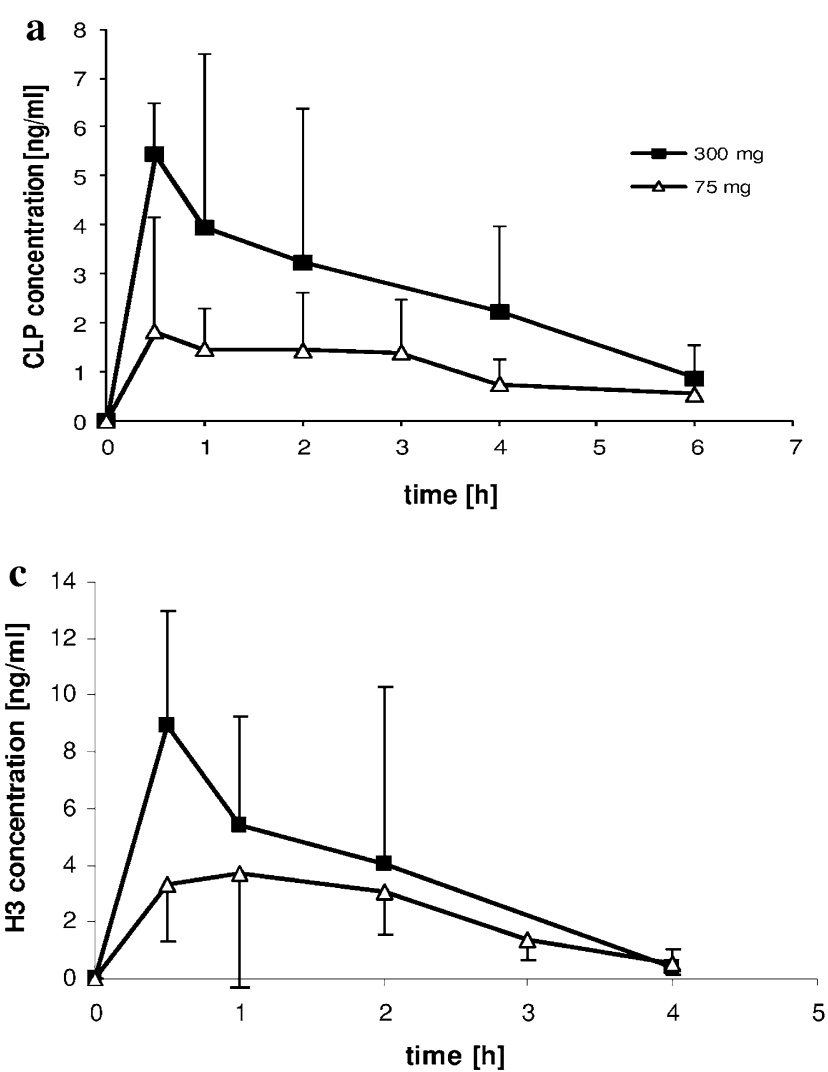

Fig. 1 Mean plasma concentrations of (a) clopidogrel (CLP), (b) the carboxylic acid metabolite of clopidogrel (CLPM), (c) the H3 isomer of the clopidogrel thiol metabolite (CTM) and (d) the H4 isomer of

\subsection{Pharmacokinetic Parameters}

The pharmacokinetic parameters calculated for clopidogrel, CLPM and the H3 and H4 isomers of CTM after
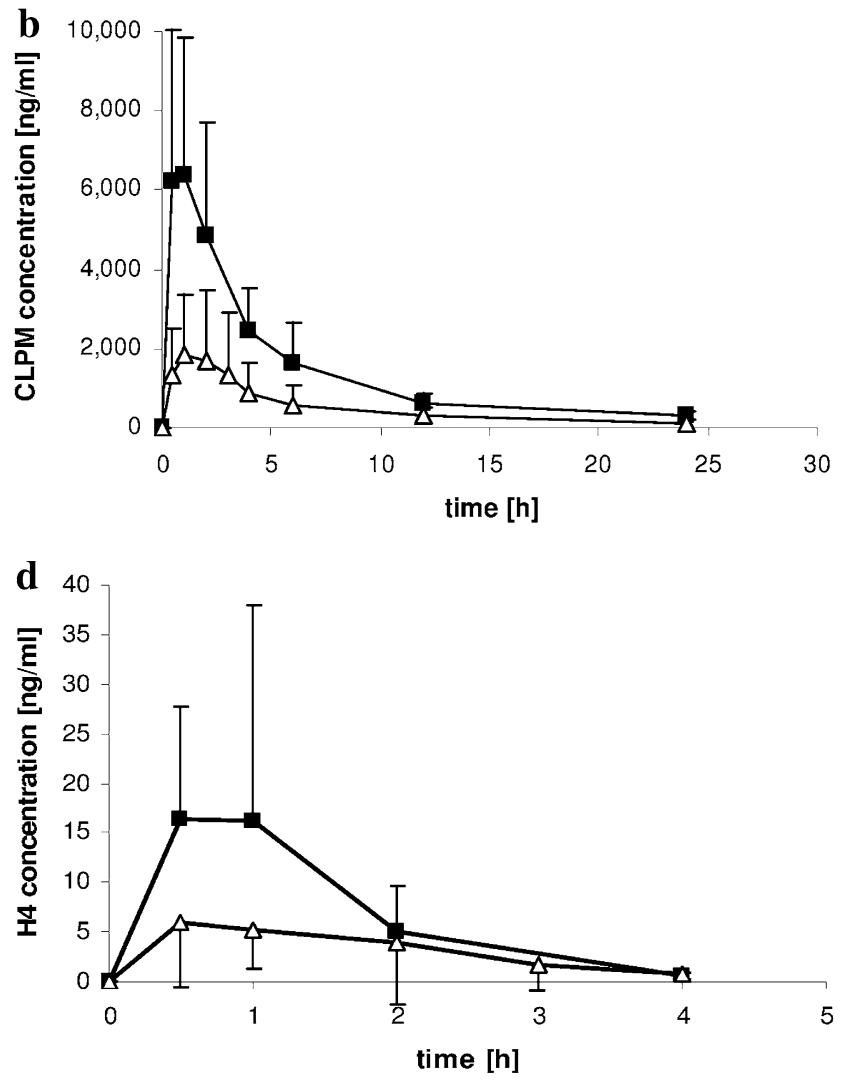

CTM versus time following administration of clopidogrel $75 \mathrm{mg}$ and $300 \mathrm{mg}$ to patients

administration of clopidogrel 75 and $300 \mathrm{mg}$ are presented in Table 2. Clopidogrel was absorbed rapidly from the gastrointestinal tract, with $C_{\max }$ values of 2 and $4.5 \mathrm{ng} / \mathrm{mL}$ following administration of clopidogrel 75 and $300 \mathrm{mg}$, 
respectively, and $t_{\max }$ values of 1.4 and $1.2 \mathrm{~h}$, respectively. The low plasma concentrations of clopidogrel resulted from its rapid metabolism. The main clopidogrel metabolite, which is the biologically inactive CLPM, reached a $C_{\max }$ in plasma that was a thousand-fold greater than that of the parent drug (Fig. 1b). The second metabolite, which is a thiol derivative of clopidogrel, was quantifiable in plasma as the $\mathrm{H} 3$ and $\mathrm{H} 4$ isomers exhibiting similar pharmacokinetic profiles (Fig. 1c, d). The plasma concentrations of the biologically active $\mathrm{H} 4$ isomer following administration of clopidogrel $75 \mathrm{mg}$ were slightly higher than those of its antipode, the inactive $\mathrm{H} 3$, whereas after a dose of $300 \mathrm{mg}$, the exposure to $\mathrm{H} 4$ was two times greater than the exposure to the $\mathrm{H} 3$ isomer (Table 2). The results were, however, strongly biased by the small number of subjects in the clopidogrel $300 \mathrm{mg}$ group. The $\mathrm{H} 3$ and $\mathrm{H} 4$ isomers were eliminated rapidly, and their concentrations were below the limit of quantification at $6 \mathrm{~h}$ after clopidogrel administration in most subjects. CLPM was characterized by the slowest elimination rate, with a $t_{1 / 2}$ of approximately $7 \mathrm{~h}$.

The statistical analysis showed that the plasma concentrations of clopidogrel and its metabolites at 1-6 $\mathrm{h}$ for clopidogrel, $1-3 \mathrm{~h}$ for $\mathrm{H} 3,0.5-2 \mathrm{~h}$ for $\mathrm{H} 4$ and $1-24 \mathrm{~h}$ for CLPM were significantly correlated with their $C_{\max }, \mathrm{AUC}_{t}$ and $\mathrm{AUC}_{\infty}$ values. A significant correlation was found between the $\mathrm{AUC}_{t}$ of the active $\mathrm{H} 4$ isomer and the $C_{\max }$ $(r=0.466, p=0.019)$ and $\mathrm{AUC}_{t}(r=0.434, p=0.049)$ of the parent drug. The differences between the pharmacokinetic parameters of the $\mathrm{H} 3$ and $\mathrm{H} 4$ isomers calculated after administration of clopidogrel $75 \mathrm{mg}$ were not statistically significant. We did not observe any statistically significant influence of age, diabetes mellitus or co-administration of CYP2C19 inhibitors (mainly PPIsomeprazole and pantoprazole) on exposure to the $\mathrm{H} 3$ and H4 isomers (Table 3).

\subsection{Pharmacodynamic Assay}

Platelet aggregation measured in patients treated with a maintenance dose of clopidogrel $75 \mathrm{mg}$ ranged between 37 and $747 \mathrm{AU} \cdot \min$ (mean \pm SD $166 \pm 146 \mathrm{AU} \cdot \mathrm{min}$, median $141 \mathrm{AU} \cdot \mathrm{min}$ ). Only two patients could be characterized as non-responders, with AUC values $>468 \mathrm{AU} \cdot \mathrm{min}$, and 14 patients had low platelet aggregation, with AUC values $<100 \mathrm{AU} \cdot \mathrm{min}$. Initially, the statistical analysis showed no correlation between platelet aggregation and the pharmacokinetic parameters, such as the $C_{\max }$ and $\mathrm{AUC}_{t}$ of clopidogrel and its metabolites, but one patient with a high value of platelet aggregation (AUC $637 \mathrm{AU} \cdot \mathrm{min}$ ) exhibited high concentrations of the active $\mathrm{H} 4$ isomer $\left(C_{\max } 23.3\right.$ $\mathrm{ng} / \mathrm{mL}$ ). After excluding that patient from the study, the statistical analysis revealed that ADP-induced platelet aggregation was strongly associated with the $C_{\max }$ of the active $\mathrm{H} 4$ isomer $[r=-0.439, p=0.025]$ (Fig. 2d). There was a trend towards a correlation of platelet aggregation and the $C_{\max }$ of the $\mathrm{H} 3$ isomer $[r=-0.374$, $p=0.063$ ] (Fig. 2c).

Table 2 Pharmacokinetic parameters of clopidogrel, the carboxylic acid metabolite of clopidogrel (CLPM) and the H3 and H4 isomers of the clopidogrel thiol metabolite

\begin{tabular}{|c|c|c|c|c|}
\hline Parameter & Clopidogrel & H3 & H4 (active) & CLPM \\
\hline Dose: clopidogrel $75 \mathrm{mg}$ & $(n=41)$ & $(n=30)$ & $(n=30)$ & $(n=45)$ \\
\hline$C_{\max }[\mathrm{ng} / \mathrm{mL} ;$ mean $\pm \mathrm{SD}]$ & $2.04 \pm 2.0$ & $5.29 \pm 5.54$ & $7.13 \pm 6.32$ & $2,516 \pm 1,754$ \\
\hline$t_{\max }[\mathrm{h} ;$ mean $\pm \mathrm{SD}]$ & $1.40 \pm 1.07$ & $1.08 \pm 0.62$ & $1.04 \pm 0.53$ & $1.37 \pm 0.74$ \\
\hline$t_{1 / 2}[\mathrm{~h} ;$ mean $\pm \mathrm{SD}]$ & $1.71 \pm 1.28$ & $0.78 \pm 0.78$ & $0.90 \pm 0.86$ & $7.14 \pm 3.32$ \\
\hline $\mathrm{AUC}_{t}[\mathrm{ng} \cdot \mathrm{h} / \mathrm{mL} ;$ mean $\pm \mathrm{SD}]$ & $5.07 \pm 3.80$ & $7.37 \pm 6.71$ & $11.30 \pm 9.58$ & $11,077 \pm 7,768$ \\
\hline $\mathrm{AUC}_{\infty}[\mathrm{ng} \cdot \mathrm{h} / \mathrm{mL} ;$ mean $\pm \mathrm{SD}]$ & $6.29 \pm 4.11$ & $7.96 \pm 6.85$ & $11.97 \pm 9.75$ & $12,383 \pm 8,552$ \\
\hline $\mathrm{CL} / F\left[\times 10^{3} \mathrm{~L} / \mathrm{h} ;\right.$ mean $\left.\pm \mathrm{SD}\right]$ & $18.96 \pm 15.89$ & - & - & - \\
\hline$V_{\mathrm{d}} / F\left[\times 10^{3} \mathrm{~L} ;\right.$ mean $\left.\pm \mathrm{SD}\right]$ & $39.24 \pm 33.52$ & - & - & - \\
\hline Dose: clopidogrel $300 \mathrm{mg}$ & $(n=3)$ & $(n=3)$ & $(n=3)$ & $(n=17)$ \\
\hline$C_{\max }[\mathrm{ng} / \mathrm{mL} ;$ mean $\pm \mathrm{SD}]$ & $4.51 \pm 3.42$ & $8.47 \pm 1.69$ & $17.92 \pm 20.38$ & $8,464 \pm 3,772$ \\
\hline$t_{\max }[\mathrm{h} ;$ mean $\pm \mathrm{SD}]$ & $1.17 \pm 0.76$ & $0.83 \pm 0.29$ & $0.83 \pm 0.29$ & $1.61 \pm 1.21$ \\
\hline$t_{1 / 2}[\mathrm{~h} ;$ mean $\pm \mathrm{SD}]$ & $1.99 \pm 0.44$ & $0.72 \pm 0.18$ & $0.84 \pm 0.20$ & $7.11 \pm 3.50$ \\
\hline $\mathrm{AUC}_{t}[\mathrm{ng} \cdot \mathrm{h} / \mathrm{mL} ;$ mean $\pm \mathrm{SD}]$ & $20.82 \pm 13.35$ & $11.24 \pm 8.31$ & $25.04 \pm 27.41$ & $32,979 \pm 12,321$ \\
\hline $\mathrm{AUC}_{\infty}[\mathrm{ng} \cdot \mathrm{h} / \mathrm{mL} ;$ mean $\pm \mathrm{SD}]$ & $21.76 \pm 13.34$ & $11.70 \pm 8.33$ & $25.69 \pm 27.54$ & $37,249 \pm 13,861$ \\
\hline $\mathrm{CL} / F\left[\times 10^{3} \mathrm{~L} / \mathrm{h} ;\right.$ mean $\left.\pm \mathrm{SD}\right]$ & $16.98 \pm 10.41$ & - & - & - \\
\hline$V_{\mathrm{d}} / F\left[\times 10^{3} \mathrm{~L} ;\right.$ mean $\left.\pm \mathrm{SD}\right]$ & $45.50 \pm 19.22$ & - & - & - \\
\hline
\end{tabular}

$A U C$ area under the plasma concentration-time curve, $A U C_{t}$ AUC from time zero to time $t, A U C_{\infty}$ AUC from time zero to infinity, $C L / F$ plasma drug clearance, $C_{\max }$ maximum plasma concentration, $t_{1 / 2}$ elimination half-life, $t_{\max }$ time to reach the $C_{\max }, V_{d} / F$ volume of distribution 
Table 3 Influence of baseline characteristics on systemic exposure to the H3 and H4 isomers of the clopidogrel thiol metabolite in patients receiving clopidogrel $75 \mathrm{mg}$

\begin{tabular}{|c|c|c|c|c|}
\hline Characteristic & $\begin{array}{l}\mathrm{H} 3 C_{\max } \\
{[\mathrm{ng} / \mathrm{mL} ; \text { mean } \pm \mathrm{SD}]}\end{array}$ & $\begin{array}{l}\mathrm{H} 3 \mathrm{AUC}_{t} \\
{[\mathrm{ng} \cdot \mathrm{h} / \mathrm{mL} ; \text { mean } \pm \mathrm{SD}]}\end{array}$ & $\begin{array}{l}\mathrm{H} 4 C_{\max } \\
{[\mathrm{ng} / \mathrm{mL} ; \text { mean } \pm \mathrm{SD}]}\end{array}$ & $\begin{array}{l}\mathrm{H} 4 \mathrm{AUC}_{t} \\
{[\mathrm{ng} \cdot \mathrm{h} / \mathrm{mL} ; \text { mean } \pm \mathrm{SD}]}\end{array}$ \\
\hline \multicolumn{5}{|l|}{ Age } \\
\hline$\geq 65$ years $(n=13)$ & $6.22 \pm 6.83$ & $8.13 \pm 8.44$ & $7.91 \pm 5.91$ & $10.40 \pm 8.07$ \\
\hline$<65$ years $(n=17)$ & $4.57 \pm 4.41$ & $6.34 \pm 4.80$ & $6.54 \pm 6.74$ & $11.48 \pm 11.03$ \\
\hline$p$ value & 0.267 & 0.629 & 0.233 & 0.923 \\
\hline \multicolumn{5}{|l|}{ Diabetes mellitus } \\
\hline Yes $(n=11)$ & $5.96 \pm 7.69$ & $7.88 \pm 9.33$ & $8.04 \pm 6.55$ & $11.69 \pm 9.63$ \\
\hline No $(n=19)$ & $4.90 \pm 4.02$ & $6.71 \pm 4.47$ & $6.61 \pm 6.30$ & $10.46 \pm 9.78$ \\
\hline$p$ value & 0.651 & 0.655 & 0.478 & 0.805 \\
\hline \multicolumn{5}{|l|}{ Proton-pump inhibitors } \\
\hline Yes $(n=13)$ & $5.94 \pm 6.63$ & $7.76 \pm 8.16$ & $9.04 \pm 8.07$ & $13.10 \pm 9.82$ \\
\hline No $(n=15)$ & $5.00 \pm 4.93$ & $7.03 \pm 5.52$ & $5.92 \pm 4.53$ & $9.69 \pm 9.81$ \\
\hline$p$ value & 0.475 & 0.980 & 0.394 & 0.277 \\
\hline
\end{tabular}

$A U C_{t}$ area under the plasma concentration-time curve from time zero to time $t, C_{\max }$ maximum plasma concentration

\section{Discussion}

To investigate the pharmacokinetics of clopidogrel and its main metabolites (CLPM and the $\mathrm{H} 3$ and $\mathrm{H} 4$ isomers of CTM) in the studied population, an HPLC-MS/MS method was developed for simultaneous determination of all of these analytes in patient plasma samples [22]. The method was adequately accurate and precise and fulfilled the validation requirements for quantitative analysis of drugs and their metabolites in biological samples. The method offered an improved LLOQ $(0.25 \mathrm{ng} / \mathrm{mL})$ of the CTM isomers compared with the LLOQ of $0.5 \mathrm{ng} / \mathrm{mL}$ previously described by Tuffal et al. [10]. The majority of the developed HPLC-MS/MS assays for determination of the active thiol metabolite of clopidogrel do not distinguish between the $\mathrm{H} 3$ and $\mathrm{H} 4$ isomers of the compound $[16,25,26]$ and may lead to overestimation of patient exposure to the active metabolite. In the present study, application of the selective HPLC-MS/MS method permitted investigation into the pharmacokinetics of the clinically relevant $\mathrm{H} 4$ isomer and the parent drug and its non-active metabolites, $\mathrm{H} 3$ and CLPM.

Pharmacokinetic data on clopidogrel, CLPM, and the $\mathrm{H} 3$ and H4 isomers of CTM are scarce and have mainly been determined in healthy volunteers. Several reports in the literature have indicated that the ethnic background of subjects has an influence on the pharmacokinetics of the parent drug. According to the published data, the $C_{\max }$ values of clopidogrel varied from $0.9 \mathrm{ng} / \mathrm{mL}$ in Argentinean subjects [27] to $4.4 \mathrm{ng} / \mathrm{mL}$ in Egyptian healthy volunteers [28] following administration of clopidogrel $75 \mathrm{mg}$. The $C_{\max }$ of $2.0 \mathrm{ng} / \mathrm{mL}$ obtained in the present study following the same dose is similar to the $C_{\max }$ values of 1.5 and $2.5 \mathrm{ng} / \mathrm{mL}$ reported by Hurbin et al. [29] in US healthy volunteers in the fasted and fed states, respectively. A possible reason for the ethnicity-specific responses is significant variability in the frequencies of the CYP2C19 allelic variants found in different ethnic groups, which may affect the metabolism of clopidogrel [30]. Clopidogrel pharmacokinetics in patients with cardiovascular disease may differ from those in healthy subjects. Sibbing et al. [31] reported diminished conversion of clopidogrel into its active thiol metabolite in patients with a history of stent thrombosis following percutaneous coronary intervention. This was reflected by a significantly lower $C_{\max }$ of CTM in patients $(3.2 \mathrm{ng} / \mathrm{mL})$ than in healthy control subjects $(14.5 \mathrm{ng} / \mathrm{mL})$ following administration of clopidogrel $600 \mathrm{mg}$. A similar conclusion may be drawn from the results of the present study, where the $C_{\max }$ values of the $\mathrm{H} 3$ and $\mathrm{H} 4$ isomers of CTM were 5.29 and $7.13 \mathrm{ng} / \mathrm{mL}$, respectively (Table 2), and were lower than those reported in healthy volunteers, according to the literature data. Following the same dose of clopidogrel $75 \mathrm{mg}$, Tuffal et al. [10] observed $C_{\max }$ values of $17.8 \mathrm{ng} / \mathrm{mL}$ for $\mathrm{H} 3$ and $16.4 \mathrm{ng} / \mathrm{mL}$ for the $\mathrm{H} 4$ isomer, but in the study by Furlong et al. [32], a $C_{\max }$ of $11 \mathrm{ng} / \mathrm{mL}$ for the $\mathrm{H} 4$ isomer was reported. We could speculate that conversion of clopidogrel into the $\mathrm{H} 4$ active isomer of the thiol metabolite was diminished in the studied group of patients, compared with healthy volunteers. One possible reason for this is impaired blood flow to the body tissues associated with cardiovascular disorders. This may result in decreased drug absorption and impaired metabolism of the drug in the liver. The higher CTM concentrations $(>20 \mathrm{ng} / \mathrm{mL})$ in plasma obtained by Peer et al. [26] resulted from application of a validated HPLC-MS/MS method that did not 

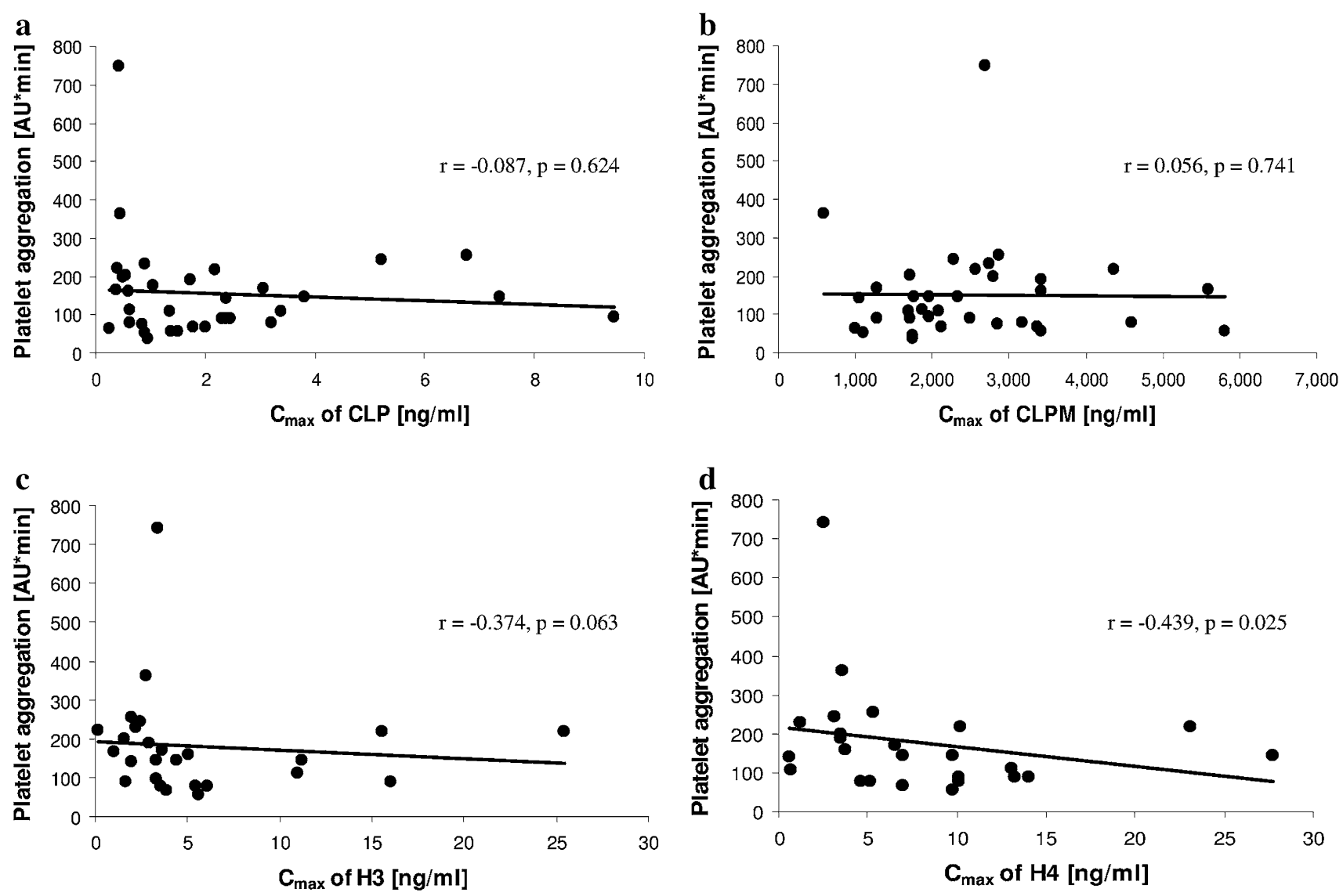

Fig. 2 Correlation between platelet aggregation and the maximum plasma concentration $\left(C_{\max }\right)$ of (a) clopidogrel (CLP), (b) the carboxylic acid metabolite of clopidogrel (CLPM), (c) the $\mathrm{H} 3$ isomer

of the clopidogrel thiol metabolite (CTM) and (d) the H4 isomer of CTM in patients receiving clopidogrel $75 \mathrm{mg}$. The solid lines represent the linear regression fit to the data. $A U$ arbitrary units

distinguish between the $\mathrm{H} 3$ and $\mathrm{H} 4$ isomers. Geisler et al. [33] reported that an impaired response to clopidogrel treatment may be predicted by certain factors, such as advanced age ( $>65$ years), a history of acute coronary syndromes, diabetes mellitus or renal failure. These variables may also have an influence on systemic exposure to the CTM isomers. In our study, neither age nor diabetes mellitus was significantly associated with the $C_{\max }$ or $\mathrm{AUC}_{t}$ of the $\mathrm{H} 3$ and $\mathrm{H} 4$ isomers (Table 3). The multivariate analysis of variance showed no association between the combination of these variables and the pharmacokinetic parameters of the CTM isomers.

As demonstrated by the aforementioned studies, the pharmacokinetics of clopidogrel and CTM are highly variable, with a CV of $50-80 \%$ for the calculated pharmacokinetic parameters [10, 29, 32]. The inter-subject variability was even more pronounced in the studied group of patients $(\mathrm{CV}>100 \%)$ and requires further explanation with reference to genetic polymorphisms of the ABCB1 and CYP isoenzymes, co-morbidities and drug-drug interactions. Identification of the sources that influence both the pharmacokinetic and pharmacodynamic responses

may be difficult because it is unclear whether these factors fully explain the variability of the response to clopidogrel treatment. In a study by Frelinger et al. [34]—despite rigorous elimination of variations in CYP2C19 polymorphisms, compliance, diet, nicotine and prescribed medications, including PPIs and statins-clopidogrel pharmacokinetics and pharmacodynamics varied widely in the studied group of healthy volunteers. The authors estimated that unidentified factors accounted for 82 and $64 \%$ of inter-subject variation in the pharmacokinetic parameters and pharmacodynamics responses, respectively.

In the present study, variability in clopidogrel pharmacodynamics measured by ADP-induced platelet aggregation was observed, and it was associated with plasma concentrations of the CTM isomers. The significant correlation between the $C_{\max }$ of the active $\mathrm{H} 4$ isomer and platelet aggregation indicates the usefulness of both factors as predictors of the patient response to clopidogrel therapy. The high platelet aggregation (747 AU.min) coexisting with low plasma concentrations of the $\mathrm{H} 4$ isomer $\left(C_{\max } 2.5 \mathrm{ng} / \mathrm{mL}\right)$ determined in one subject suggests a poor response to clopidogrel treatment and may lead to 
development of serious cardiovascular complications. According to the recent consensus opinion of Bonello et al. [24], platelet aggregation $>468 \mathrm{AU} \cdot \mathrm{min}$ in response to ADP as measured with the Multiplate analyser is a criterion for identification of patients at high risk of thrombotic events.

Some studies have demonstrated that monitoring of platelet function may be especially useful in patients with decreased clopidogrel metabolism. Such patients may be identified by genetic studies as carriers of the loss-offunction $C Y P 2 C 19 * 2$ alleles $[35,36]$.

Pharmacokinetic analysis of clopidogrel and its metabolites, especially the active $\mathrm{H} 4$ isomer, may be a useful tool for identification of patients who are at risk of high on-treatment platelet reactivity. Routine monitoring of platelet aggregation and $\mathrm{H} 4$ plasma concentrations during clopidogrel treatment may improve clinical outcomes in patients with cardiovascular diseases.

A significant correlation between concentrations at individual timepoints and the pharmacokinetic parameters $C_{\max }, \mathrm{AUC}_{t}$ and $\mathrm{AUC}_{\infty}$ of clopidogrel and its metabolites (see Sect. 3.3) suggests that less frequent monitoring of plasma concentrations for prediction of total drug exposure may be possible. The results might be useful for designing a limited-sampling strategy in which accurate information on the antiplatelet effect of clopidogrel can be obtained using plasma concentrations determined in a few blood samples at appropriate times. Strategies using a limited number of samples have proven to be useful in therapeutic monitoring of immunosuppressants [37] or anti-infective agents [38]. A significant correlation between the pharmacokinetic parameters of clopidogrel and the $\mathrm{AUC}_{t}$ of the $\mathrm{H} 4$ isomer allows for prediction of patient exposure to the active metabolite in situations when only analysis of the parent compound is available.

\section{Conclusion}

To our knowledge, this is the first study of the pharmacokinetics of clopidogrel and its main metabolites, the active $\mathrm{H} 4$ and inactive H3 and CLPM, in patients with cardiovascular diseases. Our results confirmed that pharmacokinetic data in healthy volunteers are not sufficient for accurate prediction of the therapeutic effect of clopidogrel in clinical conditions. The $C_{\max }$ of the active $\mathrm{H} 4$ isomer and platelet aggregation measured with the Multiplate analyser may serve as indicators of the patient response to clopidogrel therapy. The differences in the pharmacokinetic parameters of clopidogrel and its metabolites that were found in the studied group suggest that further studies of genetic and non-genetic sources of inter-individual variability should be performed.
Acknowledgments This work was supported by the Polish National Science Centre (NCN; grant number NN 405 419739). The authors would like to thank Artur Teżyk for assistance with HPLC-MS/MS analysis of the plasma samples. The authors have no conflicts of interest that are directly relevant to the content of this article.

Open Access This article is distributed under the terms of the Creative Commons Attribution Noncommercial License which permits any noncommercial use, distribution, and reproduction in any medium, provided the original author(s) and the source are credited.

\section{References}

1. CAPRIE Steering Committee. A randomised, blinded, trial of clopidogrel versus aspirin in patients at risk of ischaemic events (CAPRIE). Lancet. 1996;348:1329-39.

2. De Miguel A, Ibanez B, Badimón JJ. Clinical implications of clopidogrel resistance. Thromb Haemost. 2008;100:196-203.

3. Karaźniewicz-Łada M, Danielak D, Główka F. Genetic and nongenetic factors affecting the response to clopidogrel therapy. Expert Opin Pharmacother. 2012;13:663-83.

4. Taubert D, Beckerath N, Grimberg G, Lazar A, Jung N, Goeser T, Kastrati A, Schömig A, Schömig E. Impact of P-glycoprotein on clopidogrel absorption. Clin Pharmacol Ther. 2006;80:486-501.

5. Farid NA, Kurihara A, Wrighton SA. Metabolism and disposition of the thienopyridine antiplatelet drugs ticlopidine, clopidogrel, and prasugrel in humans. J Clin Pharmacol. 2010;50:126-42.

6. Mani H, Toennes SW, Linnemann B, Urbanek DA, Schwonberg J, Kauert GF, Lindhoff-Last E. Determination of clopidogrel main metabolite in plasma: a useful tool for monitoring therapy? Ther Drug Monit. 2008;30:84-9.

7. Kazui M, Nishiya Y, Ishizuka T, Hagihara K, Farid NA, Okazaki O, Ikeda T, Kurihara A. Identification of the human cytochrome $\mathrm{P} 450$ enzymes involved in the two oxidative steps in the bioactivation of clopidogrel to its pharmacologically active metabolite. Drug Metab Dispos. 2010;38:92-9.

8. Savi P, Pereillo JM, Uzabiaga MF, Combalbert J, Picard C, Maffrand JP, Pascal M, Herbert JM. Identification and biological activity of the active metabolite of clopidogrel. Thromb Haemost. 2000;84:891-6.

9. Mega JL, Close SL, Wiviott SD, Shen L, Hockett RD, Brandt JT, Walker JR, Antman EM, Macias W, Braunwald E, Sabatine MS. Cytochrome P-450 polymorphisms and response to clopidogrel. N Engl J Med. 2009;360:354-62.

10. Tuffal G, Roy S, Lavisse M, Brasseur D, Schofield J, Delesque Touchard N, Savi P, Bremond N, Rouchon MC, Hurbin F, Sultan E. An improved method for specific and quantitative determination of the clopidogrel active metabolite isomers in human plasma. Thromb Haemost. 2011;105:696-705.

11. Pereillo JM, Maftouh M, Andrieu A, Uzabiaga MF, Fedeli O, Savi P, Pascal M, Herbert JM, Maffrand JP, Picard C. Structure and stereochemistry of the active metabolite of clopidogrel. Drug Metab Dispos. 2002;30:1288-95.

12. Kim KA, Park PW, Hong SJ, Park JY. The effect of CYP2C19 polymorphism on the pharmacokinetics and pharmacodynamics of clopidogrel: a possible mechanism for clopidogrel resistance. Clin Pharmacol Ther. 2008;84:236-42.

13. Brandt JT, Close SL, Iturria SJ, Payne CD, Farid NA, Ernest CS 2nd, Lachno DR, Salazar D, Winters KJ. Common polymorphisms of CYP2C19 and CYP2C9 affect the pharmacokinetic and pharmacodynamic response to clopidogrel but not prasugrel. J Thromb Haemost. 2007;5:2429-36.

14. Frelinger AL 3rd, Lee RD, Mulford DJ, Wu J, Nudurupati S, Nigam A, Brooks JK, Bhatt DL, Michelson AD. A randomized, 
2-period, crossover design study to assess the effects of dexlansoprazole, lansoprazole, esomeprazole, and omeprazole on the steady-state pharmacokinetics and pharmacodynamics of clopidogrel in healthy volunteers. J Am Coll Cardiol. 2012;59: 1304-11.

15. Yousef A-M, Arafat T, Bulatova NR, Al-Zumyli R. Smoking behavior modulates pharmacokinetics of orally administered clopidogrel. J Clin Pharm Ther. 2008;33:439-49.

16. Takahashi M, Pang H, Kawabata K, Farid NA, Kurihara A. Quantitative determination of clopidogrel active metabolite in human plasma by LC-MS/MS. J Pharm Biomed Anal. 2008;48:1219-24.

17. Caplain H, Donat F, Gaud C, Necciari J. Pharmacokinetics of clopidogrel. Semin Thromb Hemost. 1999;25:25-8.

18. Taubert D, Kastrati A, Harlfinger S, Gorchakova O, Lazar A, von Beckerath N, Schömig A, Schömig E. Pharmacokinetics of clopidogrel after administration of a high loading dose. Thromb Haemost. 2004;92:311-6.

19. Erlinge D, Varenhorst C, Braun OO, James S, Winters KJ, Jakubowski JA, Brandt JT, Sugidachi A, Siegbahn A, Wallentin L. Patients with poor responsiveness to thienopyridine treatment or with diabetes have lower levels of circulating active metabolite, but their platelets respond normally to active metabolite added ex vivo. J Am Coll Cardiol. 2008;52:1968-77.

20. Heestermans AACM, van Werkum JW, Taubert D, Seesing TH, von Beckerath N, Hackeng CM, Schömig E, Verheugt FW, ten Berg JM. Impaired bioavailability of clopidogrel in patients with a ST-segment elevation myocardial infarction. Thromb Res. 2008;122:776-81.

21. Deray G, Bagnis C, Brouard R, Necciari J, Leenhardt AF, Raymond F, Baumelou A. Clopidogrel activities in patients with renal function impairment. Clin Drug Investig. 1998;16:319-28.

22. Karaźniewicz-Łada M, Danielak D, Teżyk A, Żaba C, Główka F. HPLC-MS/MS method for the simultaneous determination of clopidogrel, its carboxylic acid metabolite and derivatized isomers of thiol metabolite in clinical samples. J Chromatogr B. 2012;911:105-12.

23. Karaźniewicz-Łada M, Główka F, Oszkinis G. Capillary zone electrophoresis method for determination of (+)-S clopidogrel carboxylic acid metabolite in human plasma and urine designed for biopharmaceutic studies. J Chromatogr B. 2010;878:1013-8.

24. Bonello L, Tantry US, Marcucci R, Blindt R, Angiolillo DJ, Becker R, Bhatt DL, Cattaneo M, Collet JP, Cuisset T, Gachet C, Montalescot G, Jennings LK, Kereiakes D, Sibbing D, Trenk D, Van Werkum JW, Paganelli F, Price MJ, Waksman R, Gurbel PA, Working Group on High On-Treatment Platelet Reactivity. Consensus and future directions on the definition of high ontreatment platelet reactivity to adenosine diphosphate. J Am Coll Cardiol. 2010;56:919-33.

25. Delavenne X, Basset T, Zufferey P, Malouk N, Laporte S, Mismetti P. Ultra-performance LC MS/MS method for quantification of clopidogrel active metabolite. J Sep Sci. 2010;33:1968-72.

26. Peer CJ, Spencer SD, VanDenBerg DA, Pacanowski MA, Horenstein RB, Figg WD. A sensitive and rapid ultra HPLC-MS/ MS method for the simultaneous detection of clopidogrel and its derivatized active thiol metabolite in human plasma. J Chromatogr B. 2012;880:132-9.
27. Di Girolamo G, Czerniuk P, Bertuola R, Keller GA. Bioequivalence of two tablet formulations of clopidogrel in healthy Argentinian volunteers: a single-dose, randomized-sequence, open-label crossover study. Clin Ther. 2010;32:161-70.

28. El Ahmady O, Ibrahim M, Hussein AM, Bustami RT. Bioequivalence of two oral formulations of clopidogrel tablets in healthy male volunteers. Int J Clin Pharmacol Ther. 2009;47: $780-4$.

29. Hurbin F, Boulenc X, Daskalakis N, Farenc C, Taylor T, Bonneau D, LaCreta F, Cheng S, Sultan E. Clopidogrel pharmacodynamics and pharmacokinetics in the fed and fasted state: a randomized crossover study in healthy men. J Clin Pharmacol. 2012;52:1506-15.

30. Rosemary J, Adithan C. The pharmacogenetics of CYP2C9 and CYP2C19: ethnic variation and clinical significance. Curr Clin Pharmacol. 2007;2:93-109.

31. Sibbing D, Taubert D, Schomig A, Kastrati A, Von Beckerath N. Pharmacokinetics of clopidogrel in patients with stent thrombosis. J Thromb Haemost. 2008;6:1230-2.

32. Furlong MT, Savant I, Yuan M, Scott L, Mylott W, Mariannino T, Kadiyala P, Roongta V, Arnold ME. A validated HPLC-MS/ MS assay for quantifying unstable pharmacologically active metabolites of clopidogrel in human plasma: application to a clinical pharmacokinetic study. J Chromatogr B. 2013;926: 36-41.

33. Geisler T, Grass D, Bigalke B, Stellos K, Drosch T, Dietz K, Herdeg C, Gawaz M. The Residual Platelet Aggregation after Deployment of Intracoronary Stent (PREDICT) score. J Thromb Haemost. 2008;6:54-61.

34. Frelinger AL 3rd, Bhatt DL, Lee RD, Mulford DJ, Wu J, Nudurupati S, Nigam A, Lampa M, Brooks JK, Barnard MR, Michelson AD. Clopidogrel pharmacokinetics and pharmacodynamics vary widely despite exclusion or control of polymorphisms (CYP2C19, $A B C B 1, P O N 1)$, noncompliance, diet, smoking, co-medications (including proton pump inhibitors), and pre-existent variability in platelet function. J Am Coll Cardiol. 2013;61:872-9.

35. Bonello L, Armero S, Ait Mokhtar O, Mancicni J, Aldebert P, Saut N, Bonello N, Barragan P, Arques S, Giacomoni MP, Bonello-Burignat C, Bartholomei MN, Dignat-George F, Camoin-Jau L, Paganelli F. Clopidogrel loading dose adjustment according to platelet reactivity monitoring in patients carrying the $2 \mathrm{C} 19 * 2$ loss of function polymorphism. J Am Coll Cardiol. 2010;56:1630-6.

36. Mega J, Hochholzer W, Frelinger AL, Kluk MJ, Angiolillo DJ, Kereiakes DJ, Isserman S, Rogers WJ, Ruff CT, Contant C, Pencina MJ, Scirica BM, Longtine JA, Michelson AD, Sabatine MS. Dosing clopidogrel based on CYP2C19 genotype and the effect on platelet reactivity in patients with stable cardiovascular disease. JAMA. 2011;306:2221-8.

37. Ting LS, Villeneuve E, Ensom MH. Beyond cyclosporine: a systematic review of limited sampling strategies for other immunosuppressants. Ther Drug Monit. 2006;28:419-30.

38. Sprague DA, Ensom MH. Limited-sampling strategies for antiinfective agents: systematic review. Can J Hosp Pharm. 2009;62: 392-401. 